\title{
Sociedade de Plataformas e os desafios para a Comunicação Pública: o caso OBCOMP
}

\author{
Platform Society and the challenges for Public \\ Communication: the OBCOMP case
}

\author{
Bruno Kegler a,* \\ Ana Javes Andrade da Luz ${ }^{b}$ (iD)
}

Rejane de Oliveira Pozobon c

\begin{abstract}
RESUMO: Este artigo propõe a reflexão sobre os desafios para a "Rede de Comunicação CientíficoEducacional" (Weber 2017), no exercício de divulgação científica e da crítica à realidade, diante do processo de plataformização das sociedades contemporâneas. Além disso, reconhece a noção de infodemia, enquanto fenômeno associado aos processos de produção estratégica de informações maléficas ao debate público e tensionais à concretização da Comunicação Pública. Através da articulação de duas noções teóricas principais, Redes de Comunicação Pública (Weber 2007; 2011; 2017) e Sociedade de Plataformas (Van Dijck; Poell; De Wall, 2018; Van Dijck, 2019), problematiza aspectos ligados aos limites e às oportunidades do contexto comunicacional contemporâneo e, especificamente, às lógicas de captura, processamento e organização de informações das plataformas online, no âmbito da Rede de Comunicação Científico-Educacional. Como proposta de observação empírica, apresenta o Observatório da Comunicação Pública (OBCOMP), projeto sediado no Programa de Pós-graduação em Comunicação da Universidade Federal do Rio Grande do Sul (PPGCOM/UFRGS), a partir da sua comunicação na plataforma Facebook. A partir de testagem de publicações patrocinadas, constatou-se que a aderência à lógica comercial de funcionamento das plataformas, principalmente à compra de anúncios, é fundamental para o alcance comunicacional nas Redes, reforçando a ideia que a gratuidade do serviço não é suficiente para obter a visibilidade necessária à comunicação pública.
\end{abstract}

Palavras-chave: Comunicação Pública; Sociedade de Plataformas; Redes de Comunicação; OBCOMP; Facebook.

ABSTRACT: This article proposes a reflection on the challenges for the "Scientific-Educational Communication Network" (Weber 2017) on scientific dissemination and criticism of reality in the process of platformization of contemporary societies. Besides, it recognizes the notion of infodemia as a phenomenon associated with the processes of strategic production of information that is harmful to public debate and stressful to the concretization of Public Communication. Through the articulation of two main theoretical notions, Public Communication Networks (Weber 2007; 2011; 2017) and Platform Society (Van Dijck; Poell; De Wall, 2018; Van Dijck, 2019), this article problematizes aspects related to limits and opportunities in the contemporary communicational context and the logic of capturing, processing, and organizing information from online platforms within the scope of the Scientific-Educational Communication Network. As a proposal for empirical observation, it presents the Public Communication Observatory (OBCOMP). This project is hosted by the Postgraduate Program in Communication at the Federal University of Rio Grande do Sul (PPGCOM/UFRGS) and is based on its communication platform on Facebook. Based on tests with sponsored publications, it was found that adherence to the commercial logic of platform operation, especially when purchasing ads, is fundamental for the communicational reach in the Networks. It reinforces the idea that free service is not enough to obtain the visibility needed for public communication.

Keywords: Public Communication; Platform Society; Communication Networks; OBCOMP; Facebook.

\footnotetext{
a Universidade de Santa Cruz do Sul, Santa Cruz do Sul, RS, Brasil.

b Programa de Pós-Graduação em Comunicação e Informação, Universidade Federal do Rio Grande do Sul, Porto Alegre, RS, Brasil.

c Programa de Pós-Graduação em Comunicação, Universidade Federal de Santa Maria, Santa Maria, RS, Brasil.

*Correspondência para/Correspondence to: Bruno Kegler. E-mail: brunokegler@gmail.com.
}

Recebido em/Received: 07/04/2021; Aprovado em/Approved: 07/06/2021.

Artigo publicado em acesso aberto sob licença CC BY 4.0 Internacional (a)(i) 


\section{CONSIDERAÇÕES INICIAIS}

Este artigo parte da premissa de que há uma série de desafios de pesquisa sobre o fazer comunicacional das instituições federais de ensino superior e, em especial, a divulgação da produção científica em plataformas de mídia digitais. Sobretudo pelo atual contexto em que as Universidade Federais (UFs) sofrem ataques sistemáticos e necessitam justificar a sua existência e legitimidade, principalmente na área de Ciências Sociais Aplicadas e em Comunicação, sob acusação de manipulação ideológica e de exercício de ensino doutrinário a serviço de um projeto de poder autoritário.

Diante desse contexto, propomos a reflexão sobre o tensionamento permanente entre os limites do público e do privado, enquanto termos de uma dicotomia (BOBBIO, 2001), para discutir como a defesa do interesse público se estabelece ante às lógicas e regras do ecossistema online composto por plataformas privadas, tais como Google, Twitter, Facebook e Youtube. Além disso, são acrescidos os termos pós-verdade (Dunker 2017), infodemia (Zarocostas 2020) e fake news (Dourado; Gomes 2019), que contemplam o ataque sistemático às instituições que tradicionalmente ancoram a verdade em regimes democráticos, tais como o jornalismo e as Universidades. O resultado desse deslocamento, ou mesmo substituição, acarreta no reconhecimento cambiante da realidade, derivado de uma espécie de "epistemologia tribal" (Dourado; Gomes 2019), caracterizada pela assunção da verdade e da falsidade de acordo com os interesses de cada tribo.

Nas disputas em torno de legitimidade, visibilidade e credibilidade, através da Redes de Comunicação Científico-Educacional (Weber 2017), considera-se o contraste entre as dimensões normativa e factual da comunicação pública, especialmente tensionadas pelas características e condicionamentos impostos pelas plataformas online e o contexto contemporâneo.

Vista sob a ótica da metáfora das Redes (Weber 2007; 2011; 2017), a comunicação pública é compreendida pela constituição de nós ou de conexões simbólicas estabelecidas entre os atores ou sistemas de comunicação públicos ou privados, a partir de temas vinculantes, numa dinâmica sistêmica e processual estabelecida pelos modos como se formam e se desfazem esses elos no debate público, em versões e opiniões dissonantes ou consonantes entre si, seja no interior da mesma rede ou nas reações e respostas de outras Redes às opiniões e versões postas a circular. Assim, a comunicação pública é inserida numa perspectiva estratégica, pautada pelo interesse público, crucial à pluralidade de perspectivas ao debate público, à ancoragem da verdade, à tomada de decisão estatal e, consequentemente, à sustentação e qualificação da democracia.

Na conjunção mercado e tecnologia, é estabelecido o tensionamento aos valores públicos nas plataformas online, segundo Van Dijck, Poell e De Wall (2018). Para eles, processos sociais e econômicos são submetidos à ideologia neoliberal que define a arquitetura da sociedade plataformizada e que suprime o interesse público e o espaço público. Nesse sentido, a expressão "sociedade de plataformas" (Van Dijck; Poell; De 
Wall 2018) designa a relação inextricável entre plataformas online e estruturas sociais, ao sinalizar para a infiltração e convergência gradual das plataformas com as instituições e práticas offline que organizam as sociedades democráticas. A centralidade das plataformas está na consideração acerca dos modos como elas afetam transações econômicas, relações sociais e o funcionamento das instituições, de forma que Estado e governo são tensionados a ajustar as suas estruturas normativas e democráticas.

Olhar para esse cenário é um movimento em busca de compreensão sobre os limites e as oportunidades à comunicação pública, considerando-se a existência de alguns pontos limítrofes intransponíveis e intercambiáveis, ao passo que outros possam se hibridizar - como o uso de métricas para mensurar e ajustar as publicações para melhor circular em plataformas de redes sociais, por exemplo - na conjunção possível entre o público e o privado, como apoio e complementariedade, também para o diálogo com outras Redes.

Ratificando, não se trata de defender a propaganda ou o jogo à margem do interesse público, mas da análise da hibridização possível entre os parâmetros normativos que balizam as práticas de comunicação pública e a lógica corporativa, questionando-se os pontos de avanço e de retrocesso possíveis às duas dimensões. Trata-se, pois, de analisar os modos de utilizar as estratégias necessárias para alcançar as mesmas ou outras redes com o auxílio das plataformas online, estar visível para fazer parte do debate público e dos processos cognitivos de constituição da opinião.

Ademais, está em teste a hipótese de materialização da noção conceitual de Rede de Comunicação Científico-Educacional (Weber 2017), pressupondo-se a convergência de atores e de sistemas de comunicação de outras UFs e demais instituições de ensino superior do país na produção e na circulação regular de conteúdo, além do diálogo com outras Redes, favorecendo a divulgação científica, o esclarecimento e o combate à desinformação.

Este artigo obedece à seguinte estrutura: uma teorização sobre o conceito de comunicação pública, sobre a Sociedade de Plataformas e o atual contexto de infodemia, a apresentação da experiência do Observatório da Comunicação Pública (OBCOMP) - projeto desenvolvido no âmbito da Universidade Federal do Rio Grande do Sul - e uma testagem empírica a partir de suas publicações na plataforma Facebook, a fim de elucidar possíveis formas de visualização da metáfora da Rede CientíficoEducacional. Por fim, traz problematizações e considerações sobre os conceitos acionados e a testagem empreendida.

\section{COMUNICAÇÃO PÚBLICA: ATRAVESSAMENTOS E ELEMENTOS CONSTITUINTES}

A comunicação pública, compreendida como instância de qualificação, de defesa e de resistência da democracia (Weber 2017), ancora-se em duas premissas principais. A primeira, de ordem normativa, estabelece que ela deve ser defendida como princípio 
fundamental aos sistemas de comunicação do Estado; a segunda, de ordem epistemológica, considera a participação da sociedade como necessária à sustentação da democracia. É essencial, nessas diretrizes, a oferta regular de informação pelo Estado e pelos sistemas de comunicação midiáticos, oportunidades para a participação da sociedade no debate público e nos processos deliberativos decisórios, a livre expressão artística e a liberdade de cátedra na educação básica e na formação superior, enquanto práticas de formação plural e críticas para a comunicação pública. Em suma, a definição conceitual diz que é equivalente ao debate público, "acionado por temas de interesse público provocados a partir dos poderes da República, de instituições, sistemas de mídia ou redes de comunicação capazes de gerar disputa de opiniões, ações coletivas, associações, mobilizações consequentes ou não" (Weber 2017, p. 29).

Weber (2007; 2011; 2017) acrescenta ainda a noção de Redes de Comunicação Pública, iluminando as conexões comunicacionais instauradas em pontos nodais, constituídos por temas de interesse em comum entre os comunicantes. Não significa, nessa direção, pontos pacificados, mas elos que se estabelecem e se desfazem a partir de versões e de opiniões consonantes ou dissonantes no debate público. A manutenção desses elos simboliza a força e a atividade das Redes, sinalizando os indicadores que permitem aferir a qualidade do debate estabelecido, tendo como pressupostos teóricos os que ancoram a noção de comunicação pública. A metáfora da rede permite, assim, considerar uma linha vinculante, cuja tessitura é composta pela participação de atores e sistemas nos modos de verbalizar e de interpretar os conteúdos postos a circular (Weber 2017). São Redes formadas por relações de poder, cujas disputas se estabelecem em pontos de avanço e de retrocesso, de interesses públicos e privados, através das ações, reações, versões e contraversões, sobre temas cuja resolução passa pelas decisões do Estado.

Fica claro, nessa perspectiva, que as disputas discursivas e imagéticas estabelecidas nas Redes e entre as Redes têm implicações sociais, políticas, judiciais e econômicas, por exemplo. Para além disso, elas orbitam em torno desse objetivo, reconhecendo-se que são disputas pelo domínio do debate, pela hegemonia da opinião e, no limite, pelas decisões sobre as questões de interesse público que desencadearam o processo comunicacional. Pode-se compreender, nessa direção, que as Redes disputam a atenção e o apoio de outras Redes, não apenas em termos quantitativos - que representa um ganho de visibilidade - mas qualitativo, tendo como horizonte a legitimidade e a credibilidade como premissas à influência e a associação à opinião.

A legitimidade está vinculada à capacidade de liderança, de representação e de reconhecimento por diferentes instâncias, direta ou indiretamente implicadas no debate, o que incide sobre a repercussão de suas ações e opiniões. A visibilidade depende da competência técnica e profissional para desenvolver ações e produtos de comunicação para defender argumentos através de imagens, recursos jornalísticos e publicitários. Por fim, a credibilidade está vinculada ao reconhecimento dos argumentos por instâncias com legitimidade acerca do tema em debate. Na mesma 
direção, pelos impactos das ações e a repercussão em outras Redes, especialmente as estatais quanto à incidência sobre os processos deliberativos e nas decisões.

A tipologia proposta em Weber (2017) compreende as Redes que estão no âmbito do Estado, as quais são Redes de Comunicação do Poder Executivo, Redes de Comunicação do Poder Legislativo, Redes de Comunicação do Poder Judiciário e Sistemas de Comunicação e Radiodifusão Pública; no âmbito da sociedade, estão Redes de Comunicação Política; Redes de Comunicação Social; Redes de Comunicação Mercadológica; Redes de Comunicação Científico-Educacional e Redes de Comunicação Religiosa e; no âmbito dos sistemas de comunicação midiática, estão as Redes de Comunicação Mediática.

Estabelecidos esses pressupostos, o entendimento de Redes de Comunicação Pública (Weber 2007; 2011; 2017) prevê que o debate público é iniciado quando há o acionamento de temas limítrofes entre o público e o privado por uma ou mais Redes, através da emissão de opinião ou versão, de modo que reverberem e repercutam em outras Redes, instaurando um cenário concorrencial entre diversos atores e sistemas, públicos e privados, que depende da legitimidade, da visibilidade e da credibilidade para a eficácia das estratégias que conjugam "argumentos racionais e posições passionais, de dispositivos profissionais e tecnológicos, mobilizações de rua e estética própria, as redes acionam opiniões e provocam reações" (Weber 2017, p. 54). Consiste no esforço de "tentar definir a circulação sobre o poder de comunicar, controlar a comunicação e debater temas de interesse público" (idem, p. 25).

Neste estudo, interessa especificamente a noção de Redes de Comunicação CientíficoEducacional e aqui cabe uma ponderação. Apesar de as UFs estarem vinculadas ao poder executivo federal, a tipologia de Weber (2017) as insere entre as redes que estão no âmbito da sociedade. Como esclarece a autora, as instituições do Poder Executivo detêm maior capacidade de investir em comunicação e em relações com a sociedade e "tem sua comunicação efetuada em nome do Estado que governa, sem a individuação partidária ou pessoal, mesmo que isto ocorra via discursos. A defesa das redes é por um projeto de governabilidade" (Weber 2017, p. 48). Já as Redes de Comunicação Científico-Educacional são "formadas por atores e organizações que detêm o poder sobre a formação dos cidadãos e sobre a produção de conhecimento científico. As pesquisas, teses, dissertações, publicações permitem contestar, endossar ou formular proposições sobre temas de interesse público e contribuem na formulação de argumentos" (Weber 2017, p. 51-52). A sua constituição contempla, além das instituições de ensino governamentais, organizações de ensino de propriedade privada, sob o poder simbólico que Ihes confere autonomia para analisar e dizer, sob o princípio, mitificado, da neutralidade, ancorado no saber originário da experimentação. Neste sentido, é um locus diferenciado no debate público quanto à competência de contestar ou ratificar dados e argumentos vinculados a temas de interesse público.

Identifica-se então a dificuldade advinda do distanciamento entre a dimensão conceitual e os déficits da política democrática contemporânea sediada em torno dos 
meios de comunicação de massa e, mais recentemente, também das tecnologias de comunicação em rede. Em relação aos meios de comunicação de massa, é Habermas (1984) quem inaugura a crítica acerca da impossibilidade de debate público na esfera pública, ao denunciar o prejuízo ao debate público ocasionado pela organização das corporações de mídia em torno de seus próprios interesses, afeitos ao mercado e ao entretenimento. Nos termos de Gomes (2008, p. 138), "é a invisibilidade no interior da visibilidade", em referência às decisões tomadas pelos meios de comunicação a partir de critérios próprios e internos à sua produção.

É uma perspectiva paradoxal na qual se observa, de um lado, a possibilidade de potencialização da visibilidade e da discutibilidade e, de outro, os limites impostos pelo caráter intrínseco às corporações midiáticas, que estabelecem uma moldura estética e inteligível dos conteúdos produzidos e veiculados. Nas mídias digitais, é acrescida a possibilidade de descentralização do polo emissor de informações - antes centrado nos meios de comunicação massivos - e de estabelecimento de relações comunicacionais horizontalizadas entre cidadãos, considerando-se a comunicação online em plataformas. Esses aspectos são objeto de reflexão na próxima seção, tendo-se como horizonte principal os condicionamentos à comunicação pública sob a ótica da plataformização da sociedade (Van Dijck; Poell; De Wall 2018).

\section{A COMUNICAÇÃO PÚBLICA POSSÍVEL NAS PLATAFORMAS ONLINE}

A produção de conteúdos e a divulgação científica ancorados nas lógicas de funcionamento das plataformas online esbarram em indicativos que podem ser interpretados como limites e, opostamente, oportunidades. É limitante no sentido da desagregação entre conteúdo e público, pensando-se a funcionalidade do website e das mídias institucionais, por exemplo. Por outro lado, há a descentralização das organizações midiáticas enquanto esfera de visibilidade pública (Gomes 2008) e palco de disputa para as demais Redes de Comunicação Pública (Weber 2007; 2011; 2017), permitindo a diversificação de fontes e a disputa que se estabelece à margem desse protagonismo tradicional, mas que funciona a partir de lógicas algorítmicas de seleção, monetização e impulsionamento da visibilidade. Há, nesse contexto comunicacional plataformizado, o oligopólio das Big Five (Van Dijck; Poell; De Wall 2018), expressão que designa as cinco companhias que detém o domínio do fluxo de dados online: Amazon, Apple, Microsoft, Facebook e Google.

Ocorre que, entre produtores de conteúdo e operadores de plataformas como Google, Facebook e Twitter, está na mão destes a posse da "caixa preta" com o controle desses sistemas. Ao público, há diferentes caminhos para o consumo, mas que constituem uma "liberdade rastreada". Transformados em dados, as pistas deixadas são mensuradas por métricas pelos operadores de plataformas e convertidos em inteligência. A novidade em relação aos meios de comunicação offline não está no monitoramento da audiência, mas na efetividade dessa quantificação e na análise qualitativa desses dados. Como explicam Provost e Fawcett (2016), dados sociodemográficos têm seus limites à análise e são funcionais até certo volume, 
enquanto dados detalhados sobre transações individuais dos clientes ampliam significativamente o desempenho.

Nessa direção, quão maior o banco de dados utilizado, melhor o desempenho preditivo. Em tese, significa que as plataformas que detêm mais ativos de dados podem ter vantagem estratégica em relação às demais. Daí, são dialógicas as noções de big data e de data science. Big data como "conjuntos de dados que são grandes demais para os sistemas tradicionais de processamento e, portanto, exigem novas tecnologias para processá-los" (Provost; Fawcett, 2016, p. 8), Ao produtor de conteúdo, resta a compreensão dessas lógicas para a utilização, por exemplo, de softwares e métricas de avaliação dos dados gerados pela experiência dos usuários para a elaboração de estratégias de potencialização da visibilidade e do consumo.

Em relação à segunda, a supervalorização do Facebook, por exemplo, é creditada a seus vastos ativos de dados, "incluindo informações sobre pessoas e seus gostos, bem como informações sobre a estrutura da rede social" (Provost; Fawcett, 2016, p. 12). Em conjunto, os dados e a capacidade de extrair conhecimento deles formam os dois princípios fundamentais de data science, enquanto ativos estratégicos. Nesse sentido, trata-se da conjunção entre a qualidade dos dados coletados e a competência para sua análise.

A atenção recai no "entre" que há na relação entre produtores de conteúdo e usuários das plataformas, que se refere ao domínio tecnológico que configura algoritmicamente a "realidade" publicizada, por um lado, e interpretada, pelo outro. São processos que definem quais informações cada usuário e a comunidade geral irá receber, em resposta aos dados gerados pela experiência individual e coletiva na plataforma.

Elencamos aqui dois pontos principais à discussão. Primeiro, a importância da mensagem responde a uma lógica quantitativa de visibilidade. No Twitter, por exemplo, quão mais replicada a publicação, melhor o ranqueamento no tópico de tendências e o reconhecimento da comunidade. À reflexão sobre as Redes de Comunicação Pública (Weber 2007; 2011; 2017) e a comunicação das UFs, em especial, é relevante considerar a possibilidade de inflar a visibilidade e assim distorcer a relevância de um tema ou versão, potencializando seus impactos e a abrangência ante à comunidade de usuários. Trata-se, pois, da (pseudo) hegemonia da opinião, daí a sua relevância.

Em segundo, aos condicionamentos impostos pelo próprio modus operandi das plataformas online, que possibilita a utilização das tecnologias com finalidades não democráticas e a sobreposição do interesse privado ao público no debate contemporâneo, é cada vez mais presente a disseminação de mentiras, podendo estar em relatos camuflados de notícia, à sombra da credibilidade jornalística, como observam Dourado e Gomes (2019), tendo-se como premissa que a veracidade ou a falsidade estão relacionadas à consonância entre os fatos e a descrição dos fatos. 
No mesmo horizonte da noção de Fake News, pós-verdade indica uma ideia de "verdade contextual, que não pode ser escrita, posta no bolso e representada amanhã, como garantia de fidelidade, compromisso ou esperança gerada pela palavra" (Dunker 2017, p. 19). Significa dizer, nesses termos, uma verdade efêmera e circunstancial, sustentada pelo controle da memória, conforme o que se quer que seja reconhecido como verdadeiro, ao passo da epistemologia tribal, a qual fazem referência Dourado e Gomes (2019). Poder-se-ia dizer, segundo Sacramento e Paiva (2020), que a confiança estaria mais estreita à convicção e à crença do que à razão e à apresentação de provas, combinados com a projeção e a potencialização algorítmica.

Para Dunker (2017), há, no país, a expansão de um "novo irracionalismo brasileiro" caracterizado pelo ataque discursivo predatório a professores, estudantes e artistas, por exemplo, que desempenham a contestação a "verdades óbvias". Nesse sentido, trata-se de um ataque à legitimidade dessas instituições para que seja possível a verdade estruturada em uma razão universal, constituindo-se oposições dicotômicas como religião e ciência, ordem e balbúrdia, bem e mal. Para tal, aciona-se a apropriação de fatos objetivos, combinando-se "observações corretas, interpretações plausíveis e fontes confiáveis em uma mistura que é, no conjunto, absolutamente falsa e interesseira" (Dunker 2017, p.38), estrategicamente dirigida a encontrar eco nos preconceitos do interlocutor e confirmar suas teses.

Trata-se do cenário ideal à proliferação do que se compreende por infodemia, isto é, um grande aumento no volume de informações associadas a um assunto específico (como no caso da atual pandemia), com potencial de se multiplicarem exponencialmente em pouco tempo (Zarocostas 2020). Essa dinâmica favorece a disseminação de informações falsas, enviesadas ou a manipulação de dados com intenção duvidosa. "Na era da informação, esse fenômeno é amplificado pelas redes sociais e se alastra mais rapidamente, como um vírus" (OPAS 2020).

Portanto, além de potencializar a visibilidade, é possível fazê-la numa direção distópica, falseada e, claro, estrategicamente pensada a algum fim. As condições para a distorção da realidade estariam conciliadas com uma espécie de crise epistêmica, fruto do ataque às instituições credenciadas a sustentar a verdade, como as universidades e o jornalismo. Às UFs, neste contexto, e no âmbito das Redes Científico-Educacionais (Weber 2017), há o tensionamento que conduz à necessidade de ação de defesa institucional, da defesa do interesse público, além da comunicação regular destinada à divulgação da produção científica.

Como sinalizam Van Dijck, Poell e De Wall (2018), para as instituições científicas, públicas e privadas, a quem historicamente compete a ancoragem da verdade e a sustentação do sistema democrático, é necessária a compreensão da lógica de funcionamento das plataformas online, os valores estruturais vigentes e a função organizativa desempenhada na contemporaneidade. Distante da ideia de ser um "território" neutro, horizontal e plural em sua essência, trata-se de um ambiente corporativo, com implicações sociais e, inclusive, ideológicas. 


\section{O OBSERVATÓRIO DE COMUNICAÇÃO PÚBLICA (OBCOMP)}

O Observatório da Comunicação Pública é um projeto criado com o objetivo principal de tornar acessível a produção científica relacionada ao tema da comunicação pública, além de ser espaço de captura, sistematização, reflexão e crítica sobre a comunicação praticada por instituições do Estado, da mídia e da sociedade sobre temas de interesse público (Weber; Luz 2017). Sediado no Programa de Pós-graduação em Comunicação da Universidade Federal do Rio Grande do Sul (PPGCOM/UFRGS), está vinculado ao grupo de pesquisa Núcleo de Comunicação Pública e Política (Nucop), sob a coordenação da profa. Maria Helena Weber. O site do Observatório é acessado através da URL www.ufrgs.br/obcomp.

Na função de repositório, o OBCOMP oferece acesso facilitado a teses, dissertações, livros e artigos científicos referentes aos temas: comunicação pública, comunicação política, comunicação de Estado e governamental, opinião pública, esfera pública e deliberação, mobilização social, jornalismo e interesse público, mídias e internet. Além disso, lista projetos de pesquisa de professores e de grupos de pesquisa em funcionamento nas universidades brasileiras cujas produções estejam ligadas, direta ou transversalmente, ao tema da comunicação pública, divulgando ainda eventos acadêmicos do campo da Comunicação e elencando as revistas científicas da área, com indicação da sua posição no sistema de avaliação da Coordenação de Aperfeiçoamento de Pessoal de Nível Superior (CAPES).

No que tange ao acompanhamento dos sistemas de comunicação em atuação no Brasil, o site do Observatório lista as assessorias de comunicação em funcionamento nas três esferas de governo - federal, estadual e municipal -, dos poderes executivo, legislativo e judiciário, bem como as mídias públicas e governamentais existentes; compila as campanhas publicitárias realizadas por entes públicos e privados que tratem de temas de interesse público e sistematiza a legislação sobre comunicação e radiodifusão pública no Brasil.

Por fim, nas funções de monitoramento e de crítica, o Observatório publica notícias, textos opinativos, entrevistas e aulas públicas que colaboram para reflexão sobre a pesquisa em comunicação no país. Em janeiro de 2021, o OBCOMP disponibilizava mais de 400 notícias para leitura. Já entre textos opinativos, entrevistas e aulas abertas conteúdos cuja produção, editoração e publicação exigem mais tempo - o projeto totalizava cerca de 60 publicações. Esses conteúdos mantém o site em constante atualização e são também divulgados em plataformas online. Para isso, o OBCOMP possui um canal de vídeos no Youtube e uma fanpage na plataforma Facebook.

Em janeiro de 2021, a fanpage do OBCOMP contabilizava quase dois mil seguidores, sendo 1.782 residentes no Brasil e, desses, 486 pessoas em Porto Alegre (RS), cidade onde se localiza o grupo de pesquisa que mantém o projeto. Em seguida, aparece São Paulo, cidade mais populosa do país, mas que responde por menos de 10\% do número total de seguidores, com 107 pessoas. 
Esses dados indicam a capacidade de crescimento que o projeto ainda possui, nas plataformas online e, possivelmente, também no website, favorecendo a ampliação da Rede de Comunicação Científico-Educacional que o Observatório se propõe a mobilizar. Os conteúdos publicados no Facebook são uma chamada sobre o conteúdo disponível no site, convidando o/a leitor/a a ler o material na íntegra na homepage do projeto. Fotos e links personalizados também são utilizados com frequência.

Apesar dos quase dois mil seguidores, ao longo dos mais de cinco anos de presença do OBCOMP no Facebook, o que se percebe é um baixo nível de alcance e de engajamento nas publicações. De acordo com as informações fornecidas pela plataforma, cedidas pelos administradores da conta, em um intervalo de doze meses (15/01/2020 a 15/01/2021) a média foi de 200 pessoas alcançadas pelas publicações, isto é, cerca de $10 \%$ do total de seguidores (Figura 1). Já a média de reações, comentários e/ou compartilhamentos oscilou, nesse mesmo período, entre cinco e dez por publicação (Figura 2).

Figura 1. Alcance das publicações do OBCOMP no Facebook (15/01/2020 a 15/01/2021).

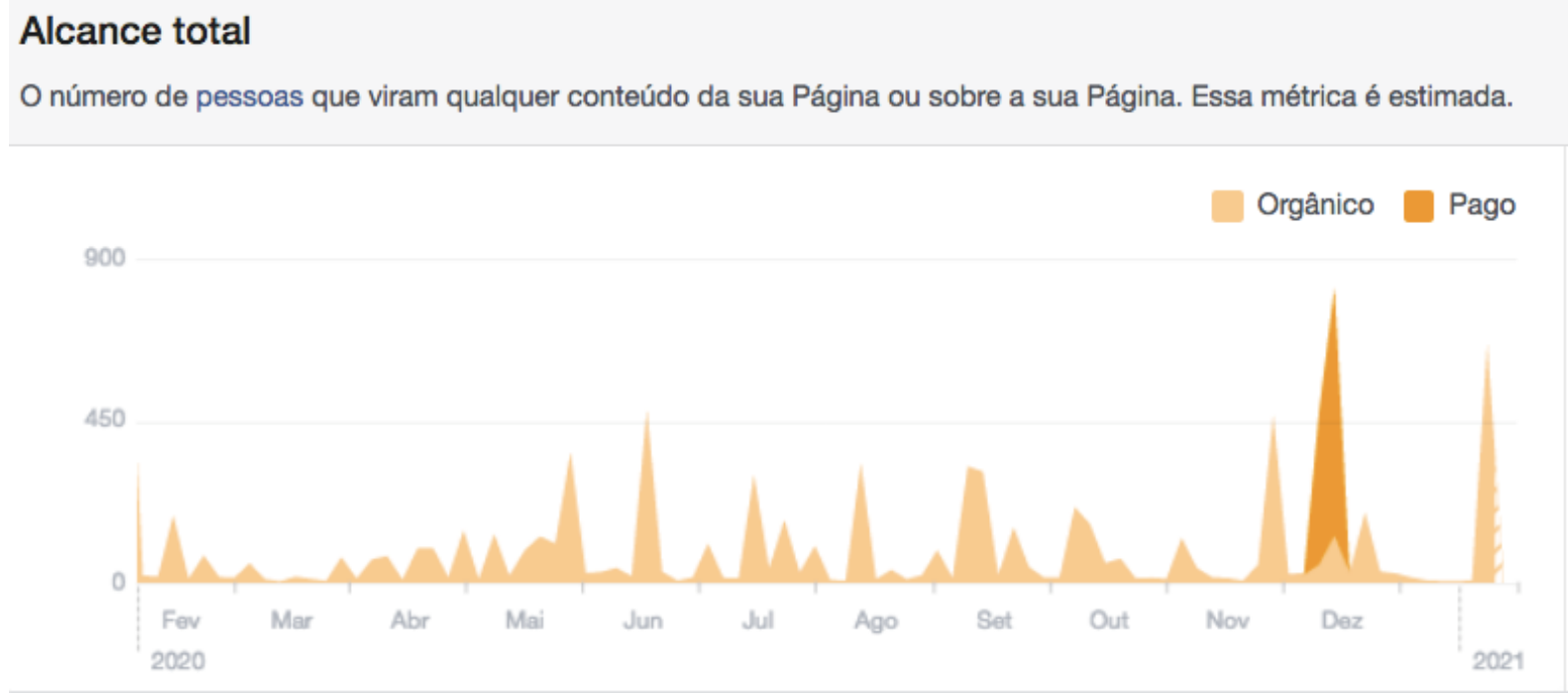

Fonte: Facebook 
Figura 2. Alcance das publicações do OBCOMP no Facebook (15/01/2020 a 15/01/2021).

Reações, comentários, compartilhamentos e muito mais

Essas ações ajudarão você a alcançar mais pessoas.

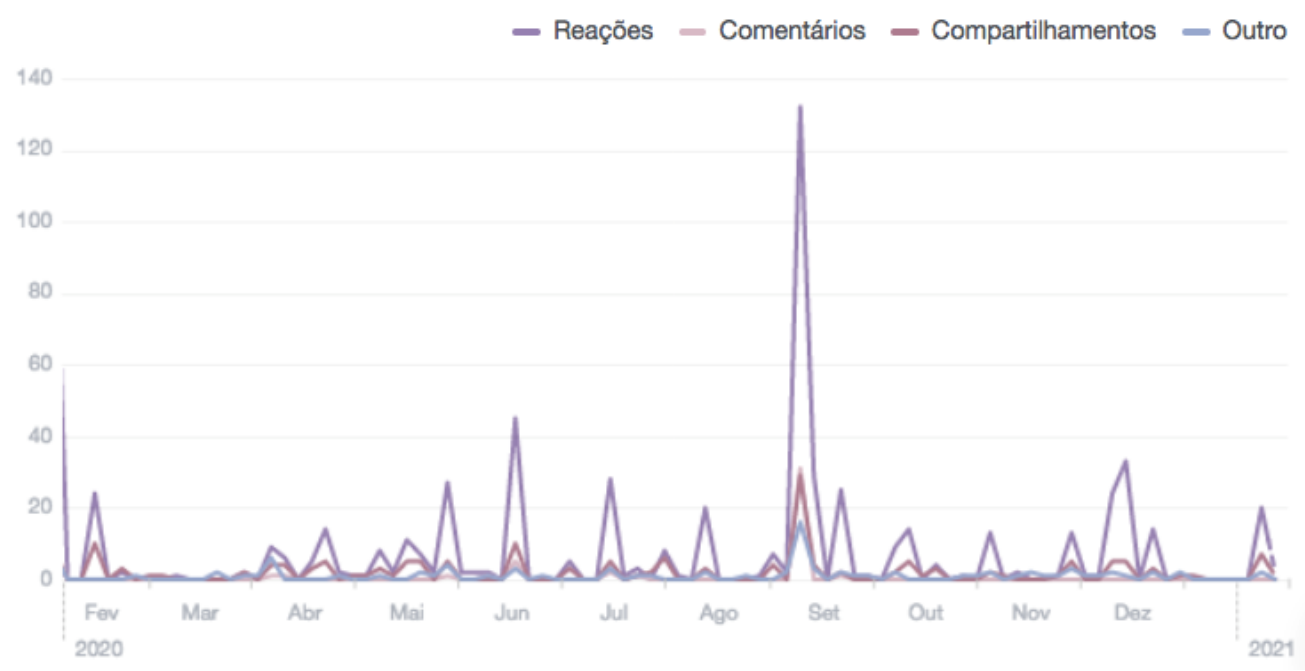

Fonte: Facebook

\section{EXERCÍCIO DE PLATAFORMIZAÇÃO DO OBCOMP: IMPULSIONANDO CONTEÚDOS}

A fim de verificar se essas métricas podiam atingir melhores resultados a partir do impulsionamento pago de conteúdos, realizamos um exercício empírico patrocinando duas diferentes publicações da fanpage. A primeira, o post de divulgação do livro "Comunicação Pública e Política: pesquisas e práticas", que apresenta reflexões e resultados de pesquisas desenvolvidas pelo grupo Núcleo de Comunicação Pública e Política - o Nucop/UFRGS; e, a segunda, a divulgação de uma entrevista com a coordenadora geral do OBCOMP, a professora Maria Helena Weber (PPGCOM/UFRGS), na qual o tema da Comunicação Pública é destaque. As duas publicações indicavam um link encurtado para acesso ao conteúdo divulgado, personalizado através do serviço bit.ly, que permite obter métricas de acesso à página.

As publicações possuem características que as diferenciam: a primeira, a divulgação do livro, foi postada originalmente em 12/07/2019 e, antes do impulsionamento, havia alcançado 20 mil pessoas, número muito superior à média observada nas publicações da página. Essa publicação também está fixada no topo da fanpage. No entanto, em virtude do tempo decorrido desde sua publicação original já não evoluía em número de curtidas ou de compartilhamento. A segunda postagem, sobre a entrevista, havia sido publicada cinco dias antes do início do impulsionamento, em 23/11/2020 e obtinha até então o desempenho médio das publicações da página, registrando até a véspera do anúncio: 11 curtidas, 03 compartilhamentos e 176 pessoas alcançadas. 
Para o teste, o público escolhido para receber as peças foi aquele que já segue a página do Observatório, com residência declarada no Brasil e sem restrição de gênero ou idade. Ambos os conteúdos foram patrocinados durante uma semana (28/11/2020 a 05/12/2020), pelo valor mínimo exigido pela plataforma para o período: $\mathrm{R} \$ 37,80$ por publicação. Os resultados, comparando o desempenho das postagens antes e depois do anúncio patrocinado, estão no Quadro 1, abaixo.

Quadro 1. Comparativo do desempenho de postagens patrocinadas na fanpage do OBCOMP

\begin{tabular}{|c|c|c|c|c|c|c|}
\hline \multirow[t]{2}{*}{ Postagem } & \multicolumn{3}{|c|}{$\begin{array}{l}\text { Livro Comunicação Pública \& } \\
\text { Política: } \\
\text { pesquisa e práticas }\end{array}$} & \multicolumn{3}{|c|}{$\begin{array}{l}\text { Entrevista com a profa. } \\
\text { Maria Helena Weber }\end{array}$} \\
\hline & $\begin{array}{l}\text { Antes do } \\
\text { anúncio }\end{array}$ & $\begin{array}{l}\text { Depois } \\
\text { do } \\
\text { anúncio }\end{array}$ & $\begin{array}{c}\text { Percentual } \\
\text { de } \\
\text { crescimento }\end{array}$ & $\begin{array}{l}\text { Antes } \\
\text { do } \\
\text { anúncio }\end{array}$ & $\begin{array}{l}\text { Depois } \\
\text { do } \\
\text { anúncio }\end{array}$ & $\begin{array}{l}\text { Percentual } \\
\text { de } \\
\text { crescimento }\end{array}$ \\
\hline $\begin{array}{c}\text { Pessoas } \\
\text { Alcançadas }\end{array}$ & 19.945 & 20.700 & $4 \%$ & 176 & 915 & $520 \%$ \\
\hline Curtidas & 164 & 225 & $37 \%$ & 11 & 80 & $730 \%$ \\
\hline Compartilhamentos & 161 & 174 & $8 \%$ & 03 & 10 & $330 \%$ \\
\hline Engajamento & 2.431 & 2.697 & $1 \%$ & 25 & 254 & $1.000 \%$ \\
\hline Cliques no link & 22 & 48 & $220 \%$ & 10 & 33 & $330 \%$ \\
\hline
\end{tabular}

Fonte: desenvolvido pelos autores com dados fornecidos pela plataforma Facebook e pelo aplicativo Bit.ly.

Pelos dados do Quadro 1, é possível constatar que apenas o ingresso e uso das plataformas não são suficientes para alcançar visibilidade ante o horizonte de seguidores da página. Em contrapartida, com o impulsionamento pago de conteúdos, as métricas revelam o aumento de curtidas, de compartilhamentos, de engajamento e de cliques no link da publicação, o que nos leva a considerar o potencial de imposição da lógica comercial sobre a comunicação pública, que aposta nos temas de interesse público e na argumentação razoável como seus principais ativos.

No caso da postagem do livro sobre pesquisas em Comunicação Pública verificou-se que o número de curtidas cresceu $37 \%$ durante a semana do anúncio em relação ao período de um ano e quatro meses desde a postagem original. Já o número de cliques no link de acesso ao livro teve crescimento exponencial de $220 \%$.

A postagem que divulgou a entrevista sobre Comunicação Pública apresentou métricas ainda mais substanciais: o número de pessoas alcançadas cresceu $520 \%$, o de curtidas 
cresceu 730\%, os compartilhamentos e cliques no link aumentaram 330\% e o engajamento com a publicação (curtidas, demonstração de emoções, comentários etc.) aumentou $1.000 \%$. Os dados comparam a semana anterior ao anúncio com a semana em que a postagem foi impulsionada financeiramente.

Contrapondo o comportamento médio dos seguidores da fanpage do Facebook, que oscila entre cinco e dez engajamentos por publicação (Figura 2), e os resultados obtidos na semana da testagem, podemos inferir que mesmo que o público do OBCOMP - professores, pesquisadores, estudantes da rede de Comunicação Científico-Educacional - esteja no Facebook e siga a página do Observatório, ele pode não ter acesso aos conteúdos postados gratuitamente. O mesmo não ocorre quando esses são patrocinados. Ou seja, a gratuidade do serviço seria apenas o primeiro passo para a visibilidade na plataforma, mas, para alcançar um número expressivo de seguidores, curtidas e compartilhamentos, é preciso adentrar na lógica comercial. Em outras palavras: estar presente não significa estar visível.

A questão que se impõe é que a lógica privada das plataformas/mídias sociais digitais é conflitante com o interesse público, marca da comunicação pública. Por isso, a comunicação de um projeto como o OBCOMP, exemplo de ator da Rede de Comunicação Científico-Educacional, tem dificuldade de alcançar outros integrantes da própria Rede caso não faça uso das ferramentas comerciais oferecidas. É possível sinalizar, nesta direção, para um pré-condicionamento à comunicação pública e ao debate público nessa plataforma, vinculado à lógica mercantil que rege o funcionamento desta.

A vinculação da visibilidade à capacidade de investimento impacta, por consequência, no processo de constituição da opinião pública, tendo-se como pressuposto a necessidade da pluralidade de perspectivas sobre os temas de interesse público. Para além, permite reflexionar acerca da indução do clima de opinião (Noelle-Neumann 1993), a partir do espiral de visibilidade e de reverberação que pode ser produzido artificialmente com perfis automatizados (bots ou robôs) e com a compra da visibilidade, construindo-se assim uma aparente hegemonia da opinião. O que é, no limite, o termômetro da vontade coletiva para as instâncias políticas decisórias.

Ademais, os resultados são ainda mais intrigantes se observados em conjunto com os ataques recorrentes à credibilidade das Universidades e da pesquisa científica, nos quais a veracidade dos conteúdos não é condição sine qua non, no atual contexto caracterizado pela disseminação de fake news (Dourado; Gomes 2019) em plataformas digitais, noção que conduz à expressão pós-verdade (DUNKER, 2017).

Nesse sentido, cabe acrescentar que o Observatório da Comunicação Pública integra a Rede Nacional de Combate à Desinformação (RNCD), criada em setembro de 2020 e que reúne pesquisadores, projetos, coletivos e instituições de todo o Brasil no combate à desinformação. Um dos principais temas abordados pelos integrantes da rede composta por projetos de fact-checking, de monitoramento de fake news, observatórios, grupos de pesquisas e revistas acadêmicas - é justamente a pandemia da covid-19 e os desafios de combater a propagação de notícias falsas ou de conteúdos 
deliberadamente enviesados para deturpar o debate sobre o tema. Trata-se, pois, da dificuldade enfrentada pela Rede de Comunicação Científico-Educacional (2017) em relação à consecução de visibilidade e, por derivação, de oferta de subsídios ao debate público e à constituição de elos ou pontos nodais na articulação simbólica em torno de temas de interesse público, que está na gênese da comunicação pública e da sua função de sustentação e fortalecimento do regime democrático.

Essas considerações adquirem relevo ante à centralidade organizativa que as plataformas digitais ocupam na contemporaneidade, como salientam Van Dijck, Poell e De Wall (2018). Nesse sentido, cabe ressaltar que, ainda que o exercício empírico aqui proposto tenha se restringido à plataforma Facebook, é possível estender o entendimento para outras plataformas digitais, tais como Google e Youtube, que também trabalham com a lógica de impulsionamento de conteúdos patrocinados. As empresas determinam, através de algoritmos não revelados, quem vê e quais conteúdos, deixando ao usuário opções restritas para definir a quais conteúdos terá acesso para a formação da opinião. Está em tela, portanto, a discussão sobre o interesse público ante o modelo de negócios das Big Techs, cuja rentabilidade e dominação são diretamente proporcionais à sua capacidade de captura de dados, numa lógica de retroalimentação. É desta relação entre o público e o privado que se estabelecem os tensionamentos que norteiam a reflexão dessas linhas sobre a comunicação pública possível em plataformas digitais.

\section{CONSIDERAÇÕES FINAIS}

O excesso de oferta de informação e o avanço das tecnologias digitais têm transformado os processos de comunicação, as relações e a vida em sociedade. Olhando para esse cenário, este artigo teve o intuito de refletir sobre os desafios da Comunicação Pública diante do processo de plataformização das sociedades contemporâneas, considerando o contexto de infodemia. Primeiramente propôs uma articulação teórica entre os conceitos de Redes de Comunicação Pública (Weber 2007; 2011; 2017) e Sociedade de Plataformas (Van Dijck; Poell; De Wall 2018; Van Dijck 2019), tentando apontar como esses conceitos se conectam e quais são os limites e as possibilidades na divulgação científica ancorada nas lógicas de funcionamento das plataformas no âmbito da Rede de Comunicação Científico-Educacional.

A observação empírica feita na página que o Observatório da Comunicação Pública (OBCOMP) mantém na plataforma Facebook lança reflexões sobre a tensão entre a adesão à lógica comercial dessas plataformas e a manutenção dos seus princípios basilares, ancorados no conceito de comunicação pública. A análise demonstra que a gratuidade do serviço não é suficiente para o alcance da visibilidade necessária à comunicação pública. Diante do observado, ilumina-se uma chave analítica, que pode ser objeto de investigações futuras que envolvam o OBCOMP ou outra iniciativa que se dedique aos mesmos fins. 
Vivenciamos o que Saad (2020) traduz como uma "plataformização das relações sociais", configurada por uma abundância comunicativa desequilibrada, resultado da hiperconexão proporcionada pelo uso de diversos dispositivos tecnológicos, que acarreta a fragmentação e a superficialização da comunicação. Temos à disposição um grande volume de conteúdos, no qual múltiplas vozes se apresentam, deliberam e criam novas relações. Isso modula as relações e cria um comportamento social e comunicativo coletivo (Saad 2020).

Além disso, enfrentamos o que se compreende por infodemia, isto é, um grande aumento no volume de informações circulantes mas cuja dinâmica favorece a disseminação de informações falsas e enviesadas, associadas à manipulação de dados com intenção duvidosa (Zarocostas 2020).

A comunicação pública, imersa nesse contexto, se vê frente a uma dualidade, pois, ao mesmo tempo em que temos uma infinidade de dispositivos advindos do processo de digitalização que "possibilitam uma ação comunicativa veloz, imediata, desintermediada, desterritorializada e equalizadora de vozes e hierarquias" (Saad 2020, p. 153); temos a "necessidade de ressignificação do que tradicionalmente era entendido como comunicação e sociedade" (Saad 2020, p. 153).

A estrutura da sociedade de plataformas vai interferir na seleção das informações que o usuário terá acesso e tomará como relevante. O excesso de conteúdo disponível faz com que os indivíduos filtrem e repliquem opiniões ancoradas em motivações pessoais e percepções individuais, em uma espécie de curadoria, fazendo com que algumas informações ganhem visibilidade e outras não.

As opiniões públicas construídas a partir desse contexto acabam legitimando algumas visões de mundo, ao mesmo tempo em que algumas pautas acabam momentaneamente silenciadas, no mesmo esforço estratégico de construção da hegemonia artificial da opinião. Somado a isso, temos as implicações da pós-verdade, que nos faz substituir a razão pela emoção, fazendo com que determinados grupos ou pessoas passem a aderir mais facilmente a opiniões que estejam alinhadas as nossas crenças, em uma constante tentativa de confirmação daquilo que julgamos ser o mais assertivo.

Nesse sentido, o argumento principal é que esses três pontos acima destacados, a saber: 1) o excesso de informação, muitas vezes direcionado para um uso estratégico; 2) o papel desempenhado pelos algoritmos na seleção, circulação e oferta das informações e 3) a constante busca de confirmação das nossas crenças faz com que se amplie a dificuldade de indivíduos olharem para além de seus círculos e reforcem opiniões que já compartilham. Temos, assim, uma considerável redução da diversidade, do debate e, consequentemente, da construção de uma comunicação pública de qualidade que cumpra seus objetivos de qualificação e defesa da democracia.

Para que o circuito de plataformas possa contribuir para a qualificação e reflita a ordem democrática, será necessário que as sociedades implementem os valores públicos em 
seu design, em contraponto ao atual modelo arquitetônico, estruturado para atender exclusivamente valores econômicos e interesses corporativos. Desse modo, quanto mais setores sociais são penetrados por esse sistema, maior o poder político acumulado pelos operadores dessas plataformas, numa relação dialógica que conjuga a técnica e o social. Em contraste, somente em havendo a convergência - possível e equilibrada - entre valores públicos e econômicos - podemos vislumbrar um quadro potencial de transformações e de qualificação do debate público.

Ao Observatório da Comunicação Pública, cabe atentar para os limites da plataformização de suas práticas, tendo em vista que escapa à sua essência a disputa monetária pela visibilidade. Cabe ressaltar que se trata de um projeto sem financiamento público ou privado e sem fins lucrativos.

Ao mesmo tempo, impõe-se a reflexão sobre seu papel na atualidade e a importância da Rede de Comunicação Científico-Educacional, da qual faz parte e cujo fortalecimento está entre seus objetivos, como repositório acadêmico e espaço de crítica. Afinal, importa não apenas produzir, agrupar e disponibilizar conteúdos vinculados à pesquisa em Comunicação Pública e a temas de interesse público. É preciso problematizar, igualmente, sobre formas de circulação e de acesso a essas informações. Em tempos de fragilidade democrática, de crises epistemológicas e da opacidade que marca os processos comunicacionais, a atividade do Observatório está relacionada ao papel da ciência e da Comunicação Pública no fortalecimento do conhecimento e da democracia.

\section{FINANCIAMENTO}

O presente trabalho foi realizado com apoio da Coordenação de Aperfeiçoamento de Pessoal de Nível Superior - Brasil (CAPES) - Código de Financiamento 001.

\section{REFERÊNCIAS}

BOBBIO, N. Estado, Governo, Sociedade: para uma Teoria Geral da Política. São Paulo: Paz e Terra, 2001.

DOURADO, Tatiana; GOMES, Wilson. O que são, afinal, fake news, enquanto fenômeno de comunicação política? In: Congresso da Associação Brasileira de Pesquisadores em Comunicação E Política, 8., 2019, Brasília, DF. Anais [... ]. Brasília, DF: UnB, 2019. p. 1-25.

DUNKER, C. Subjetividade em tempos de pós-verdade. In: DUNKER, C. (et. al.). Ética e pós-verdade. Porto Alegre: Dublinense, 2017.

GOMES, W. Da discussão à visibilidade. In: GOMES, W; MAIA, R.C.M. Comunicação e democracia: Problemas \& Perspectiva. São Paulo: Paulus, 2008. 
HABERMAS, J. Mudança estrutural na Esfera Pública: investigações quanto a uma categoria da sociedade burguesa. Jürgen Habermas: tradução de Flavio R. Kothe. 2. ed. Rio de Janeiro: Tempo Brasileiro, 1984.

NOELLE-NEUMANN, Elisabeth. The spiral of silence: public opinion, our social skin. 2. ed., Chicago: University of Chicago Press, 1993.

OPAS, Organização Pan-Americana da Saúde. Entenda a infodemia e a desinformação na luta contra a covid-19. OPAS, 2020. [Acesso em 03 de março de 2021] Disponível em https://iris.paho.org/bitstream/handle/10665.2/52054/Factsheet-

Infodemic_por.pdf?sequence $=14$

PROVOST, F.; FAWCETT, T. Data Science para negócios. Rio de Janeiro, RJ: Alta Books, 2016.

SAAD, Elizabeth. A plataformização das relações sociais: reflexões sobre a ressignificação da atividade comunicativa. In: FARIAS, L.; LEMOS, E.; REBECHI, C. Opinião pública, comunicação e organizações: convergências e perspectivas contemporâneas. São Paulo: Abrapcorp, 2020, p. 152-163.

VAN DIJCK, J. A Sociedade da Plataforma: entrevista com José van Dijck. DigiLabour, 2019. [Acesso em 06 de maio de 2020] Disponível em

https://digilabour.com.br/2019/03/06/a-sociedade-da-plataforma-entrevista-com-josevan-dijck/.

VAN DIJCK, J.; POELL, T.; DE WALL, M. The Platform Society: public values in a connective world. Oxford: Oxford University Press, 2018.

WEBER, Maria Helena; LUZ, Ana Javes. Observatório da Comunicação Pública: pesquisa, crítica e cidadania. Comunicação \& Inovação (online), v. 18, p. 01-17, 2017.

WEBER, Maria Helena. Na Comunicação Pública, a captura do voto. LOGOS 27, Mídia e Democracia, Rio de Janeiro, ano $14,2^{\circ}$ semestre de 2007. (p. 21-42)

WEBER, Maria Helena. Estratégias da comunicação de Estado e a disputa por visibilidade e opinião. In: Comunicação Pública, sociedade e cidadania. São Caetano do Sul, SP: Difusão, 2011.

WEBER, Maria Helena. Nas Redes de Comunicação Pública, as disputas possíveis de poder e visibilidade. In: Weber, Maria Helena; Coelho, Marja Pfeifer; Locatelli, Carlos (Org.). Comunicação Pública e política - pesquisa e práticas. Florianópolis: Insular, 2017.

ZAROCOSTAS, J. How to fight an infodemic. The Lancet, 395(10225), 676, 2020. [Acesso em 03 de março de 2021] Disponível em https://www.thelancet.com/action/showPdf?pii=S0140-6736\%2820\%2930461-X 